\title{
INCREASED ATTRACTION OF ORYCTES RHINOCEROS AGGREGATION PHEROMONE, ETHYL 4-METHYLOCTANOATE, WITH COCONUT WOOD
}

\author{
By \\ Ambrosio Raul R. Alfiler ${ }^{1}$
}

\begin{abstract}
Trapping experiments at the Zamboanga Research Center of the Philippine Coconut Authority provided evidence of the resultant synergistic activity of the combination of the Oryctes rhinoceros aggregation pheromone, Ethyl 4-methyloctanoate, and old coconut wood in pheromone traps. Traps containing both old coconut wood and aggregation pheromone caught significantly more rhinoceros beetles than traps containing the pheromone or old coconut wood alone. The use of selective trapping using the aggregation pheromone presents a new option for the reduction of the beetle population in the field and control of this important pest of coconut palm in the Philippines.
\end{abstract}

\section{INTRODUCTION}

Recently, a male-produced aggregation pheromone of O. rhinoceros (Morin et. al., 1996; Hallet, et.al., 1995) was discovered and identified as ethyl 4-methyloctanoate. Preliminary trials at the Philippine Coconut Authority-Zamboanga Research Center (PCA-ZRC) (Alfiler, 1997; 1998) using the laboratory synthesized pheromone for mass trapping of rhinoceros beetles proved to be promising. This has opened new prospects for Oryctes trapping using a powerful attractant. However, it is still unclear if there are any plant volatiles that could likely enhance attraction of the aggregation pheromone to rhinoceros beetles similar to Rhynchophorus aggregation pheromone which requires the presence of synergistic plant volatiles for maximum pheromone attraction (Gries et.al., 1993; Rochat, et.al., 1995).

These trials were done as part of the attempts to optimize trapping conditions for the use of the aggregation pheromone for mass trapping of rhinoceros beetles in the Philippines. This report presents evidence of the synergistic effect of old coconut wood on the Oryctes aggregation pheromone.

\section{MATERIALS AND METHODS}

Bucket traps consisted of a covered 9-10gal plastic pail with four $2 \mathrm{~cm} \times 7 \mathrm{~cm}$ openings at the sides and a central hole $(\mathrm{dia} .=6 \mathrm{~cm}$.) on the plastic cover. The pails were mounted $1.7 \mathrm{~m}$ from the ground on a cement post. The Oryctes pheromone was provided by INRA (France) and placed in Kartel $^{\mathrm{TM}}$ tube dispensers ( 2 tubes together per trap). The pheromone was suspended from the plastic cover inside the pail. Under Zamboanga conditions (average temp $=27.76^{\circ} \mathrm{C} ; \mathrm{RH}=89.43$; mean daily rainfall $=7.59 \mathrm{~mm}$ ), the pheromone diffusion rate was approx. $10 \mathrm{mg} /$ day.

There were three treatments, namely: traps with pheromone and coconut wood, pheromone alone and coconut wood alone. Pieces of coconut shell were placed in the traps with pheromone alone to provide a medium for the beetles to hide during the daytime and avoid escaping during nighttime.

\footnotetext{
${ }^{1}$ Philippine Coconut Authority-Zamboanga Research Center, San Ramon P.O. Box 356 Zamboanga City 7000, Philippines.
} 
Coconut wood used in the traps was collected from the surrounding coconut plantations. They were from 15-20 year old palms that had been cut down during the past $1.5 \mathrm{~B} 2$ years. The coconut wood was cut into pieces approx. $200 \mathrm{~cm}^{3}$. The wood from different sources was mixed together. The bucket traps were filled up to about $2 \mathrm{in}$. from the top with several pieces of old coconut wood.

The trials were conducted from November, 1998 to January, 1999 at the PCA-Zamboanga Research Center in an 11-hectare area with moderate to high Oryctes damage. The site had a planting density of about 180 palms/ha with the coconut palms planted $8 \mathrm{~m} \mathrm{x} 8 \mathrm{~m}$ triangular. Plots contained 1 to 2 year old coconut seedlings.

The number of male and female Oryctes caught in the traps were recorded twice a week for 7 weeks. Female beetles caught in the traps were dissected to determine the state of their ovaries. As a comparison, female beetles caught in breeding sites and from palms were also dissected.

The trapping experiment was designed as Randomized Complete Block with equal replications. There were 3 groups (treatment) of 5 similar traps each. The traps in each group were approx. 5m apart and each group of traps was at least $150 \mathrm{~m}$ apart. Every week the position of each group of 5 traps was interchanged (re-randomized). Two separate trials were conducted. The first was set-up inside a recently established coconut plantation containing 1-2 year old palms and the second still within the same plantation but $150 \mathrm{~m}$ from the first block.

Results were analyzed using a one-way analysis of variance on total captures after data transformation to square root of $(x+2)$. The means were compared using Duncan=s Multiple Range Test (DMRT).

\section{RESULTS AND DISCUSSION}

Table 1 shows the number of male and female beetles caught in the pheromone traps with or without old coconut wood. Traps containing coconut wood alone failed to attract beetles despite the fact that the wood was considered to be highly suitable for Oryctes egg laying/breeding. The old coconut wood was collected in the field and always contained eggs, larvae and/or adults of $O$. rhinoceros at the time of collection (all the insects were removed before the wood was placed in the traps). Traps containing the pheromone alone caught a fairly good number of rhinoceros beetles but traps containing both pheromone and old coconut wood caught significantly more beetles $(\mathrm{P}<0.05)$ than traps containing the pheromone alone.

Male and female beetles were caught in almost the same frequency (Figure 1) in traps containing the pheromone alone or in combination with coconut wood $\left(\mathrm{X}^{2}=0.79,4 \mathrm{df}\right)$. Previous $O$. rhinoceros trapping trials at the Zamboanga Research Center (Alfiler, 1997; 1998) also showed that there were no significant differences in the proportion of females and males caught in traps containing ethyl 4-methyloctanoate (Figure 2). This is in contrast to previously reported studies where more females than males were caught in the traps containing the pheromone (Morin, et.al., 1996).

It was evident that old coconut wood produced plant volatiles/secondary compounds that enhanced the attractiveness of the pheromone to rhinoceros beetles. Alone, the plant volatiles produced by the coconut wood did not attract rhinoceros beetles either because the amount produced was insufficient or the volatiles required the presence of other chemicals/substances to be effective in attracting beetles. The Oryctes aggregation pheromone together with the volatiles produced by the old coconut wood resulted in a synergistic action between the two compounds that increased trapping efficiency compared to using the pheromone or coconut wood alone. With Rhynchophorus palmarum 
trapping, Rochat et al. $(1991,1993)$ demonstrated that there was synergism between the R. palmarum pheromone and plant additives (coconut or oil palm wood, sugarcane) placed in the weevil traps.

Dissection of the females caught in the pheromone traps in this study, as well as those collected from previous trials (Alfiler, 1997; 1998) showed that there were more females $(76 \%$, $\mathrm{N}=456)$ ) that had already mated and contained full-size eggs in their ovaries than unmated females without full-sized eggs (Table 2). This was significant at 5\% level $\left(X^{2}=126.321 \mathrm{df}\right)$. This was also observed in female beetles collected from breeding sites $\left(87 \%, \mathrm{~N}=8 ; \mathrm{X}^{2}=4.5\right)$. However, among beetles caught feeding in palms, there were significantly more females without full-sized eggs in their ovaries $\left(27 \%, \mathrm{~N}=103 ; \mathrm{X}^{2}=21.45\right)$. It was evident that the aggregation pheromone attracted mature beetles that were in search of a possible mate or breeding sites for egg laying.

Zelazny and Alfiler (1987) found that the adult life of $O$. rhinoceros was divided into periods of feeding and periods of breeding. After leaving their pupation sites, beetles started to feed in palms. This was followed by a breeding phase. Mating took place not only in breeding sites but also in palms (Zelazny, 1975; Zelazny and Alfiler, 1987). In breeding sites, males and females occurred together. The females usually arrived first and the males followed after eggs have been laid. The males stayed longer in the breeding sites to prepare more wood for the larvae (Zelazny and Alfiler, 1991). Finally, there was a late-life feeding phase where, occasionally, the beetles made additional visits to palms (Zelazny and Alfiler, 1987). Selective trapping of mature beetles could, therefore, reduce the number of reproducing adults in the field.

Gas chromatography, olfactometry and electroantennography would be able to identify these plant volatiles in old coconut wood and confirm the response of the beetles to these chemicals alone and in combination with the Oryctes aggregation pheromone. Identification of these synergistic chemicals followed by their successful laboratory synthesis can lead to the production of a truly powerful synthetic attractant that can be used for mass trapping of Oryctes rhinoceros.

\section{ACKNOWLEDGEMENT}

Thanks and much appreciation are due to Dr. Jean Francois Julia of the Centre de Cooperation Internationale en Recherche Agronomique pour le Development (CIRAD), France and Dr. Jean Paul Morin of the Institute National de la Recherche Agronomique (INRA), France for the pheromone, suggestions in the conduct of the trials and comments on the manuscript. 


\section{REFERENCES}

ALFILER, A.R.R. 1997. Oryctes rhinoceros trapping at PCA-Zamboanga Research Center. Zamboanga City. mimeographed report, $7 \mathrm{p}$.

ALFILER, A.R.R. 1998. Selective trapping of Oryctes rhinoceros with an aggregation pheromone at the PCA-Zamboanga Research Center. Zamboanga City. mimeographed report, 8p.

GRIES, G., R. GRIES, A.L. PEREZ, A.C. OEHLSCHLAGER, L.M. Gonzalez. H.D. PIERCE Jr., M. KOUDA-BONAFOS, M. ZEBEYOU and N. NANOU 1993. Aggregation pheromone of the African palm weevil, Rhynchophorus phoenicis). Naturwissenschaften 80:90-91.

HALlET, R.H., A.L. PEREZ, G. GRIES, R. GRIES, H.D. PIERCE Jr.,J. YUE, A.C. OEHLSCHLAGER, L.M. GONZALES and J.H. BORDEN 1995. Aggregation pheromone of the coconut rhinoceros beetle, Oryctes rhinoceros (L.) (Coleoptera:Scarabaeidae). J. Chem Ecol. 21: 1549-1570.

MORIN, J.P., D. ROCHAT, C. MALOSSE, M. LETTERE, R.D. de CHENON, H. WIBOWO and C. DESCOINS.1996. Ethyl 4-methyloctanoate, major component of Oryctes rhinoceros (L.) (Coleoptera, Dynastidae) male pheromone. C.R. Acad. Sci. Paris 319:595-602.

ROCHAT, D., F. AKAMOU, A. SANGARE, D. MARIAU and K. MORI. 1995. Field trapping of Rhynchophorus phoenicis with stereoisomers of the synthetic aggregation pheromone. C.R. Acad. Sci. Paris 318: 183-190.

ZELAZNY, B. 1975. Behaviour of young rhinoceros beetles, Oryctes rhinoceros. Entomol. Exp. and Appl., 18:135-140.

ZELAZNY, B. and A.R. ALFILER 1987. Ecological methods for adult populations of Oryctes rhinoceros (Coleoptera: Scarabaeidae). Ecological Entomology 12:227-238.

ZELAZNY, B. and A.R. ALFILER 1991. Ecology of baculovirus-infected and healthy adults of Oryctes rhinoceros (Coleoptera:Scarabaeidae) on coconut palms in the Philippines. Ecological Entomology 16:253-259. 
Table 1: Number of $O$. rhinoceros caught in traps with and without the ethyl 4-methyloctanoate and old coconut wood*

\begin{tabular}{|l|r|r|r|r|}
\hline \multicolumn{1}{|c|}{ Trial 1 Treatment } & Male & Female & Total & \multicolumn{1}{c|}{ Mean } \\
\hline Pheromone with coconut wood & 67 & 79 & 146 & $73 \mathrm{a}$ \\
Pheromone alone & 43 & 42 & 85 & $42.5 \mathrm{~b}$ \\
Coconut wood alone & 0 & 2 & 2 & $1 \mathrm{c}$ \\
\hline
\end{tabular}

\begin{tabular}{|l|r|r|r|r|}
\hline Trial 2 Treatment & Male & Female & Total & Mean \\
\hline Pheromone with coconut wood & 68 & 67 & 135 & $67.5 \mathrm{a}$ \\
Pheromone alone & 18 & 26 & 44 & $22 \mathrm{~b}$ \\
Coconut wood alone & 1 & 0 & 1 & $0.5 \mathrm{c}$ \\
\hline
\end{tabular}

-figures indicate total twice weekly catches for 7 replicates with 5 traps/treatment means in the same column with the same letter are not significantly different at 5\% level (DMRT)

Table 2: Comparison of physiological condition of female $\mathbf{O}$. rhinoceros from traps, palms and breeding sites

\begin{tabular}{|l|c|c|c|}
\hline \multicolumn{1}{|c|}{ Collection site } & O with full-sized eggs & O without full-sized eggs & N \\
\hline Traps & $76 \% \mathrm{a}$ & $24 \% \mathrm{~b}$ & 458 \\
Palms & $27 \% \mathrm{~b}$ & $73 \% \mathrm{a}$ & 103 \\
Breeding sites & $87 \% \mathrm{a}$ & $13 \% \mathrm{~b}$ & 8 \\
\hline
\end{tabular}

For each collection site, percentages with the same letter are not significantly different at $6 \%$ level (X2 test) 